It has been our experience (unpublished) that boxers fractures with a volar angulatio $\mathbb{P}$ of greater than $30^{\circ}$ is associated with pain, deformity and a decrease in grip strength This corresponds to Lowdon (1986), who showed that residual angulation was relate $\$$ to the severity of pain and Abdon (1984) who showed that a greater angulation caused $\stackrel{\mathbb{R}}{\mathbb{R}}$ more severe disibility. We therefore find it difficult to accept the conclusion drawn b $\overrightarrow{\mathrm{F}^{*}}$ Porter et al., (1988) that functional outcome is not significantly related to the degree of residual angulation, and that these fractures do not require treatment.

The recent trend of immediate mobilization (Arafa et al., 1986; Ford et al., 1989) o simple methods of treatment like volar slab (Porter et al., 1988) we feel have beed prompted because these fractures are difficult to reduce and maintain in externat splintage (McKerrell et al., 1987). Our study shows that these difficulties can bẹ overcome and adequate external splintage achieved by the method described.

We conclude that fractures of the fifth metacarpal neck with a volar angulation ow greater than $30^{\circ}$ can be effectively reduced and maintained by this method of externa splintage, which is easy to learn and can be performed by suitably experienced Accidenti and Emergency staff.

A. MAITRA \& B. SEN

Accident and Emergency Department,

Royal Victoria Infirmary,

Newcastle upon Tyne, England

\title{
REFERENCES
}

Abdon P., Muhlow A. \& Stigsson L., (1984) Subcapital fractures of the fifth metacarpal bone Archives 0 Orthopaedic Trauma Surgery 103, 231-4.

Arafa M., Hains J., Noble, J. (1986) Immediate mobilization of fractures of the fifth metacarpal neck. Injur $\$$ 17, 277-8.

Ford D. J., Ali M. S. \& Steel W. M., (1989) Fractures of the fifth metacarpal neck: Is reduction of immobilisation? fournal of Hand Surgery, 14B, 165-7.

Lowden I. M. R. (1986) Fractures of the metacarpal neck of the little finger. Injury 17, $189-92$.

McKerrell J., Vaughan Bowen J. \& Geoffrey J., et al (1987) Boxers fractures-conservative or operative management. Fournal of Trauma 27 486-90.

Porter M. L., Hodgkinson J. P. \& Hirst P. (1988) The Boxers fracture: a prospective study of functionaib recovery. Archives of Emergency Medicine 5, 212-5.

\section{The use of catgut in the primary closure of scalp wounds in children}

Sir

I am writing about the article in the September issue, Volume 6, page 216 regarding the use of catgut in the primary closure of scalp wounds in children. It surprised me to see that the use of absorbable sutures in the closure of scalp wounds is worthy of inclusion in your journal. We have been using absorbable sutures not only for children's scal wounds but also for adults and not only on the scalps but elsewhere, where cosmesis is not a problem, for at least 3,000 lacerations a year for many years now. Indeed I was 
under the impression that most Accident and Emergency Departments use this material. It somewhat alarms me to realize that perhaps this is not the case. Catgut is much more inert than it used to be and is quite safe to use for skin closure not only in scalps but also particularly in finger tip injuries, where the use of non-absorbable sutures is barbaric as removal is so painful.

My only quibble would be that chromic catgut is not necessary. Plain catgut is perfectly adequate providing proper directions are given to the patient to keep the wound dry for 5 days.

It is perhaps worthy of mention that the use of glue has now begun to supersede the use of any suture material in scalps, and in particular children are appropriate subjects for this method.

\section{W. FLOWERS}

Accident and Emergency Department

The General Infirmary

Leeds, England

\section{Coroner's post-mortem reports}

Sir

I recently reviewed a consecutive series of 275 coroner's post-mortem reports on patients who had passed through Lewisham Hospital's Accident \& Emergency Department. The reports were compared with the clinical notes and those in which there were discrepancies between the two were scrutinized further. They were divided into four categories:

(1) A clinically unsuspected lesion was found at post-mortem.

(2) A clinically suspected lesion was looked for but not found.

(3) A clinically suspected lesion was not looked for.

(4) Miscellaneous discrepancies including mixtures or (2) and (3) above.

Post-mortems are performed to confirm or refute clinical diagnoses. Category (3) above should therefore not exist; yet it accounted for $21.5 \%$ of the 275 reports studied.

Sixty seven patients had died following trauma and $40.3 \%$ came into category (3). This percentage was the same for hip and non-hip trauma. None of these post-mortems had been performed by hospital pathologists.

It is particularly important if injury scoring is to be used to audit the performance of $A \& E$ departments, that we are able to obtain full and accurate post-mortem reports. It may be that the pathologists had merely omitted to mention the presence of normal findings, but this appears to be unlikely. These examinations are carried out rapidly in order to find $a$ cause of death and are difficult for A\&E staff to attend; being outwith the hospital.

It is imperative that post-mortems for multiple trauma are done properly, but I have sympathy for the overworked pathologist who only has $10 \mathrm{~min}$ per body. However, it seems to me that formal coroner's post-mortems on patients with isolated hip fractures are completely unproductive. In the series I looked at, these patients had been in 